\title{
O PLANEJAMENTO URBANO NA CONSTRUÇÃO DA CIDADE SUSTENTÁVEL: ELEMENTOS PARA A MORADIA DIGNA ${ }^{1}$
}

\author{
URBAN PLANNING IN THE CONSTRUCTION OF THE \\ SUSTAINABLE CITY: ELEMENTS FOR DIGNA DWELLING
}

\author{
Juvêncio Borges Silva ${ }^{2}$ \\ Juliana Castro Torres ${ }^{3}$ \\ Paula Martins da Silva Costa
}

\begin{abstract}
RESUMO
O artigo tem o objetivo de analisar as diretrizes do planejamento urbano para a concreção da moradia com dignidade. O planejamento urbano institui diretrizes de organização das áreas habitáveis, promovendo à população um ambiente ecologicamente equilibrado e organizado, com condições dignas de sobrevivência para todos, visando à dignidade da pessoa humana, com o mínimo existencial à vida dos cidadãos, implicando que o Estado deve traçar, conceber, implementar e executar políticas públicas capazes de tornar a moradia como um direito mínimo de existência. Embora o ordenamento contemple vasta legislação sobre os temas, não só de normas nacionais, como também internacionais, demonstrando a grande preocupação com os institutos, observa-se que ainda existem grandes desafios para que sejam aplicados devido a fatores como a especulação imobiliária e a omissão do Poder Público, o que acarreta grandes problemas como o da exclusão urbanística. A pesquisa se caracteriza como sendo teórica e
\end{abstract}

\footnotetext{
${ }^{1}$ O presente trabalho foi realizado com apoio da Coordenação de Aperfeiçoamento de Pessoal de Nível Superior - Brasil (CAPES) - Código de Financiamento 001.

${ }^{2}$ Pós-doutorado em Direito pela Faculdade de Direito da Universidade de Coimbra (2010), Doutor em Sociologia pela Universidade Estadual Júlio de Mesquita Filho - UNESP (2005), Mestre em Sociologia pela Universidade de Campinas - UNICAMP (2000), Graduado em Direito pela Faculdade de Direito de Franca (1997), Graduado em Ciências Sociais pela Faculdade de Filosofia de Passos - FAFIPA (1992), Especialização em Didática e Planejamento do Ensino Superior pela Faculdade de Filosofia de Passos - FAFIPA (1992). É docente titular a-m da Associação de Ensino de Ribeirão Preto e do Centro Educacional Hyarte - ML Ltda. É docente do Programa de Mestrado e Doutorado em Direitos Coletivos e Cidadania da Universidade de Ribeirão Preto. (jsilva@unaerp.br). ${ }^{3}$ Mestre em Direitos Coletivos e Cidadania pela Universidade de Ribeirão Preto - UNAERP. Especialista em Direito Público Lato Sensu pela Universidade Anhanguera - UNIDERP. Graduada em Direito pela Universidade do Estado de Minas Gerais - Unidade Passos. Advogada, inscrita na OAB/MG sob o no 121.202 - Escritório de Advocacia com experiência nas áreas de Direito Privado e Público. Foi Bolsista de Gestão em Ciência e Tecnologia BGCT-III pela FAPEMIG. Foi Bolsista PROSUP-CAPES. É membro do Conselho Municipal da Cidade de Passos-MG. É Professora de Direito, no curso de Direito da Universidade do Estado de Minas Gerais/UEMG Unidade Passos. É Coordenadora do Núcleo de Assistência Judiciária Gratuita - NAJ da UEMG - Unidade Passos. (jucastrotorres@ hotmail.com)

${ }^{4}$ Possui graduação em Direito pela Universidade de São Paulo - USP (1992). Iniciação Científica pela Fundação de Amparo à Pesquisa do Estado de São Paulo - FAPESP (1992). Especialização em Direito Civil e Processual pela Universidade de Franca (2000). Especialização em Direito Público pela Universidade de Brasília - UNB (2010). Mestranda em Direitos Coletivos e Cidadania na Universidade de Ribeirão Preto - UNAERP com bolsa da CAPES-PROSUP (2019). Advogada da União desde 2000. Vice-Presidente da Comissão Advocacia Pública da Ordem dos Advogados do Brasil - Seccional de Ribeirão Preto e Membro da Comissão Estadual Advocacia Pública da Ordem dos Advogados do Brasil Seção São Paulo. (paula.costa.pmdsc@gmail.com).
} 
bibliográfica e o método de procedimento é o dedutivo, valendo-se de material histórico, sociológico e jurídico, a partir de livros e artigos científicos.

\title{
PALAVRAS-CHAVE:
}

Planejamento urbano; cidade; moradia; dignidade; sustentabilidade.

\begin{abstract}
The article aims to analyze the guidelines of urban planning for the construction of housing with dignity. Urban planning establishes guidelines for the organization of habitable areas, promoting to the population an ecologically balanced and organized environment, with conditions worthy of survival for all, aiming at the dignity of the human person, with the minimum existential to the lives of citizens, implying that the State must outline, design, implement and execute public policies capable of making housing as a minimum right of existence. Although the regulation contemplates vast legislation on the themes, not only of national norms, but also international, demonstrating the great concern with the institutes, it is observed that there are still great challenges for them to be applied due to factors such as real estate speculation and omission the Public Power, which causes great problems such as urban exclusion. The research is characterized as being theoretical and bibliographic and the method of procedure is the deductive one, using historical, sociological and legal material, from books and scientific articles.
\end{abstract}

\section{KEYWORDS:}

Urban planning; city; dwelling; dignity; sustainability.

\section{INTRODUÇÃO}

A população cresce e se movimenta a cada dia e com maior frequência nos centros urbanos, em busca de melhores condições de vida e trabalho, ocasionando um crescimento geralmente desordenado do ambiente urbano.

O que se verifica nas cidades em geral é uma ocupação inadequada do solo, por falta geralmente ocasionada pela falta de promoção de políticas públicas pela Administração Municipal, favorecendo e aumentando a exclusão urbanística, o que afeta o direito à moradia.

O planejamento urbano tem como fator essencial a dignidade da pessoa humana, se traduz como um instrumento capaz de instituir diretrizes de organização das áreas habitáveis, 
proporcionando ao Estado conceber, implementar e executar políticas públicas capazes de implementar a moradia como um direito mínimo de existência do indivíduo na sociedade.

O direito à moradia digna se caracteriza como elemento essencial ao mínimo existencial e, concomitantemente, ao Estado Democrático de Direito, amparado no texto constitucional e em pactos internacionais se mostra um fator muito importante para a coletividade.

No entanto, embora exista vasta legislação nacional e internacional que garanta a promoção do direito à moradia digna, existem muitos fatores que impedem e/ou violam este direito, pelo que o presente artigo vem analisar as diretrizes do planejamento urbano e como ele pode auxiliar na concreção da moradia digna, um dos pilares do direito fundamental da dignidade humana.

Sendo assim, o presente artigo vem analisar as diretrizes do planejamento urbano para a concreção da moradia digna e como a legislação vigente pode assegurar a concreção dos direitos fundamentais do cidadão.

Para tanto, a pesquisa foi desenvolvida a partir de pesquisa bibliográfica e teórica, nas áreas de direito constitucional, civil, urbanístico e administrativo, sendo que os dados das fontes pesquisadas foram analisados por processo metodológico dedutivo, valendo-se de material histórico, sociológico e jurídico, a partir de livros e artigos científicos.

$\mathrm{O}$ artigo inicia-se com um estudo sobre o planejamento urbano como fator necessário à construção de uma cidade sustentável, passando-se em seguida à análise da propriedade e a função que ela exerce na concreção na concreção do direito à moradia com dignidade como elemento essencial ao mínimo existencial.

Ao final, conclui-se que conclui-se que, embora exista vasta legislação a fim de garantir a moradia digna, não só por normas nacionais, como também internacionais, o que demonstra a grande preocupação com o instituto, ainda existem grandes desafios para que este direito se cumpra, podendo-se destacar a omissão do Poder Público na promoção de políticas públicas capazes de garantir o direito fundamental à dignidade da pessoa humana, que por muitas vezes, por interesses políticos e privados, não cria as condições necessárias para a implementação dos fundamentos do Estado Democrático de Direito. 


\section{PLANEJAMENTO URBANO E CIDADE SUSTENTÁVEL}

Com raízes no Iluminismo, o planejamento urbano ganhou algumas particularidades durante os anos do Welfare State, período marcado por um grande crescimento econômico, com uma significativa distribuição de renda por um lado e, por outro, com um maciço investimento em políticas sociais. ${ }^{5}$

O período de maior desenvolvimento urbano se iniciou com a criação da Política Nacional de Desenvolvimento Urbano - PNDU, que integrou o II Plano Nacional de Desenvolvimento Urbano - PNDU, em 1973, durante o regime militar. ${ }^{6}$

Com o desenvolvimento mercadológico e consequente crescimento acelerado das populações nos centros urbanos gerou-se uma ocupação inadequada do solo, ocasionando o que chamam de Crise Urbana ou Hiperurbanização.

A Crise Urbana se instaura e se espraia por influência de mudanças no contexto internacional, a derrocada do socialismo real, a financeirização da economia, o crescimento explosivo da dívida externa, a revolução tecnológica, a chamada reestruturação produtiva e os novos modos de gestão e regulação do trabalho, com sua esteira de precarização do emprego e ampliação das desigualdades. ${ }^{7}$

Castells enumera características da urbanização latino-americana como fatores desta Hiperurbanização:

população urbana sem medida comum com o nível produtivo do sistema; ausência de relação direta entre emprego industrial e crescimento urbano; grande desequilíbrio na rede urbana em benefício de um aglomerado preponderante; aceleração crescente do processo de urbanização; falta de empregos e de serviços para as novas massas urbanas e, consequentemente, reforço da segregação ecológica das classes sociais e polarização do sistema de estratificação no que diz respeito ao consumo. ${ }^{8}$

\footnotetext{
${ }^{5}$ MARICATO, Ermínia. Brasil 2000: qual planejamento urbano?. Cadernos IPP UR, Rio de Janeiro, Ano XI, Nos 1 e 2, 1997. Disponível em: < https://erminiamaricato.files.wordpress.com/2016/12/cadernos-ippur.pdf>. Acesso em: 10 jul 2019. p. 1.

${ }^{6}$ MARICATO, Ermínia. As ideias fora do lugar e o lugar fora das ideias. Planejamento urbano no Brasil. In: ARANTES, Otília; VAINER, Carlos; MARICATO, Ermínia. A cidade do pensamento único. 8 $^{\text {a }}$ ed. Petrópolis: Vozes, 2013. p. 126-127.

${ }^{7}$ MINISTÉRIO DAS CIDADES. Política Nacional de Desenvolvimento Urbano 1. Novembro, 2004. p. 2 e 7 e 29.

${ }^{8}$ CASTELLS, Manuel. A Questão urbana. 3. ed. Rio de Janeiro: Paz e Terra, 1983. p. 99.
} 
Essa "Crise" se caracteriza pelo mau uso dos recursos naturais e pelo aumento da desigualdade social.

Neste ponto bem coloca Rolnik ao dizer que:

O espaço urbano deixou de se restringir a um conjunto denso e definido de edificações para significar, de maneira mais ampla, a predominância da cidade sobre o campo. Periferias, subúrbios, distritos industriais, estradas e vias expressas recobrem e absorvem zonas agrícolas num movimento incessante de urbanização. ${ }^{9}$

A falta de controle sobre o uso e a ocupação do solo ocasiona inúmeras consequências, tanto sociais como também ambientais. Podemos citar as inundações e desmoronamentos, que tanto escutamos nos noticiários e que, geralmente, atingem a população de baixa renda, na maioria dos casos alocada nas periferias das cidades, em áreas carentes de infraestrutura.

Estes fatores se dão pela ausência de planejamento urbano, ou digamos "omissão" deste por parte dos Administradores.

$\mathrm{Na}$ tentativa de contornar a situação de desigualdade estabeleceram-se normas de planejamento urbano sustentável, uma legislação que trata de normas urbanísticas e que vem lutando para uma melhor construção da cidade, com o incentivo e interesse da população.

Norberto Bobbio $^{10}$ já expressava que as mudanças no tecido social implicam no nascimento de novos direitos, o que faz com que o quadro geral normativo, apoiado em tradicionais categorias jurídico-normativas, se amplie, para atender não apenas a fatores econômicos, expresso pelo aumento da tutela de bens, antes excluídos de proteção, mas particularmente para compreender o homem não como um ser abstrato.

As normas urbanísticas buscam disciplinar os espaços habitáveis pelo homem, sejam eles urbanos ou rurais, preocupadas com a importância da habitação, trabalho, lazer e circulação na comunidade.

Sendo assim, note-se que a urbanização é uma tendência da sociedade moderna, que se movimenta e, necessita de ser ordenada para que se atenda o bem-estar social.

\footnotetext{
${ }^{9}$ ROLNIK, Raquel. O que é cidade. $4{ }^{\text {a }}$ Ed. São Paulo: Brasiliense, 2012. p. 12.

${ }^{10}$ BOBBIO, Norberto. A era dos direitos. Trad. Carlos Nelson Coutinho. Rio de Janeiro: Campus, 1992. p. 68.
} 
Ordenar o crescimento da cidade é estritamente necessário, devendo-se promover o adequado parcelamento do solo para que a cidade exerça sua função e desenvolva um bom funcionamento.

Na visão de Mukai ${ }^{11}$ "o urbanismo é concebido em termos funcionais e racionais, com uma preocupação básica humana, isto é, com valores espirituais, visando o homem no contexto urbano e a melhoria das suas condições de vida".

Este complexo de normas urbanísticas, denominado Direito Urbanístico, finaliza a organização do solo buscando proporcionar melhores condições de vida às pessoas. Ele interpreta e sistematiza as normas e os princípios que disciplinam o espaço urbano para atender a coletividade.

De acordo com Hely Lopes Meirelles este direito aponta as diretrizes básicas para se alcançar um planejamento urbano adequado:

O conjunto de medidas estatais destinadas a organizar os espaços habitáveis, de modo a propiciar melhores condições de vida ao homem na comunidade. Entenda-se por espaços habitáveis todas as áreas em que o homem exerce coletivamente qualquer das quatro funções sociais: habitação, trabalho, circulação, recreação. ${ }^{12}$

Dentro deste ordenamento podemos destacar a Lei $6.766 / 79$ que dispõe sobre o parcelamento do solo urbano e dá outras providências de cunho urbanístico e, o Estatuto das Cidades previsto pela Lei 10.257/2001, grandes marcos no desenvolvimento e organização das cidades.

A lei de parcelamento do solo orienta o projeto e a execução de qualquer obra dentro do município, assegurando as normas de urbanização para que sejam respeitados os interesses coletivos e os direitos fundamentais do ser humano e, o Estatuto da Cidade atribuiu competência à Lei municipal para demandar sobre o parcelamento do solo, dispondo em seu artigo $5^{\circ}$, caput, que:

Art. 5. Lei municipal específica para área incluída no plano diretor poderá determinar o parcelamento, a edificação ou utilização compulsórios do solo urbano não edificado, subutilizado ou não utilizado, devendo fixar as condições e os prazos para implementação da referida obrigação.

\footnotetext{
${ }^{11}$ MUKAI, Toshio. Direito urbano-ambiental brasileiro. 2. ed. Rev. e ampl. São Paulo: Ed. Dialética, 2002. p. 16.

${ }^{12}$ MEIRELLES, Hely Lopes. Direito Municipal Brasileiro. Malheiros. 16. ed. São Paulo: 2008. p. 522.
} 
Importante destacar os dizeres de Wolff acerca das diretrizes do Estatuto da Cidade:

\begin{abstract}
O Estatuto da Cidade teve a proposta inédita de agregar valores impregnados de justiça, democracia e solidariedade, inserindo-se em um contexto de barreira à imobilidade e à inércia, representando um marco fundamental de conscientização e mudanças de comportamento a médio e a longo prazos à disposição de todo cidadão brasileiro. Aliando a busca permanente do desenvolvimento urbano em bases sustentáveis ao esforço contínuo de instauração da justiça social e ambiental nas cidades, o Estatuto opõe-se à destruição do ambiente e ao aviltamento do homem, o que representa um imenso desafio para o País e suas instituições. ${ }^{13}$
\end{abstract}

Assim, temos muitas leis que tratam do processo de urbanização, que buscam a ordenação das cidades, com a correta ocupação do solo, atendendo a função social que deve ser exercida, mas, porém, como expõe Maricato ${ }^{14}$ “o poder legal do executivo federal sobre o desenvolvimento urbano, em especial sobre seu aspecto central, que é o controle sobre uso e ocupação do solo, é muito pequeno".

A Autora ainda explica que as cidades brasileiras estão como estão não por falta de planos e leis, mas por interesses políticos e problemas culturais. ${ }^{15}$

Cite-se neste ponto como bem colocado por Ermínia Maricato "o analfabetismo urbanístico", a desinformação da sociedade sobre a história da cidade e sobre o orçamento municipal, a alienação sobre o espaço geográfico e urbano no Brasil, fatores que prejudicam a sustentabilidade da cidade. ${ }^{16}$

Portanto, fator importante está a necessidade de conscientização da população no desenvolvimento de maior interesse sobre os anseios de sua cidade, para que se pratique a participação cidadã e se aplique o ideal modelo de cidade sustentável.

Assegurando-se a participação democrática, destaca-se o Plano Diretor Participativo, considerado e definido pelo Estatuto da Cidade como instrumento básico para a política de desenvolvimento e expansão urbana.

\footnotetext{
${ }^{13}$ WOLFF, Simone. Estatuto da Cidade: A Construção da Sustentabilidade..., Revista Jurídica Virtual - Brasília, vol. $4, \quad$ n. $45, \quad$ fev. 2003.40 Disponível $\quad$ em https://revistajuridica.presidencia.gov.br/index.php/saj/article/view/754/745. Acesso em 13 jul 2019. p. 9.

${ }^{14}$ MARICATO, Ermínia. O impasse da política urbana no Brasil. 3ª ed. Petrópolis: Vozes, 2014. p. 53.

${ }^{15}$ MARICATO, Ermínia. O impasse da política urbana no Brasil. 3ª . ed. Petrópolis: Vozes, 2014. p. 53-54.

${ }^{16}$ MARICATO, Ermínia. O impasse da política urbana no Brasil. $3^{a}$. ed. Petrópolis: Vozes, 2014. p. 54.
} 
Como fator principal está a prevalência democrática no seu processo de implementação, com a garantia da concretização da cidadania, liberdade e justiça, o que o caracteriza como a manifestação mais latente da gestão democrática de uma cidade.

Este instrumento é considerado como uma importante ferramenta para as cidades que enfrentam a expansão horizontal ilimitada, avançando sobre áreas frágeis ou de preservação ambiental, pois, aponta diretrizes básicas de planejamento urbano para organização da cidade, com o adequado uso e ocupação do solo, medidas de prevenção contra irregularidades privadas, medidas para o desenvolvimento sustentável com melhor distribuição de renda, moradia digna, educação, transporte, redução da criminalidade.

Em contrapartida Maricato ${ }^{17}$ afirma que o Plano Diretor "oferece discurso de boas intenções, mas distante da prática" e que "o Plano Diretor está desvinculado da gestão urbana".

No mesmo diapasão, Maricato expõe a real situação nas cidades, em que:

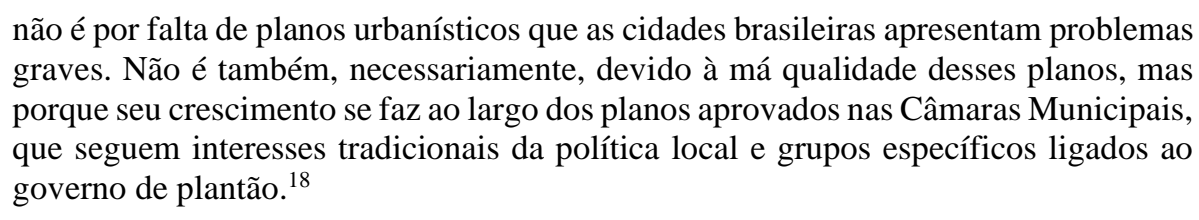

No entanto, a conscientização cidadã é um fator de extrema importância para que haja eficácia na aplicação do planejamento urbano e consequente melhoria das condições de vida. É necessário deixar o egoísmo de lado e entender que todos devem ser beneficiados, que todos tem os mesmos direitos e merecem ter dignidade.

Mesmo esta questão gerando um impasse pelo fato de ser o homem um ser de "natureza egoísta", capaz de pensar apenas em si mesmo, atrapalhando o bom desenvolvimento das relações na cidade, importante promover a conscientização de que o que é bom para todos é melhor e, uma cidade bem organizada, só se faz crescer, diminui as desigualdades, diminui a criminalidade, aumentam-se as oportunidades.

\footnotetext{
${ }^{17}$ MARICATO, Ermínia. As ideias fora do lugar e o lugar fora das ideias. Planejamento urbano no Brasil. In: ARANTES, Otília; VAINER, Carlos; MARICATO, Ermínia. A cidade do pensamento único. $8^{\text {a }}$. ed. Petrópolis: Vozes, 2013. p. 124.

${ }^{18}$ MARICATO, Ermínia. As ideias fora do lugar e o lugar fora das ideias. Planejamento urbano no Brasil. In: ARANTES, Otília; VAINER, Carlos; MARICATO, Ermínia. A cidade do pensamento único. 8ª ed. Petrópolis: Vozes, 2013. p. 124.
} 
Contudo, notadamente é a necessidade de ordenação das cidades, com um maior empenho e participação da população, para que perpetuem os direitos aos cidadãos.

Acompanhando o estudo, deve-se observar alguns princípios que limitam o uso do solo, regendo o direito de propriedade, para que os direitos fundamentais do cidadão não sejam violados, para o que bem estar individual não ultrapasse o bem estar da coletividade, pelo que passamos ao estudo da propriedade e a função que ela deve exercer na sociedade.

\section{A PROPRIEDADE E A FUNÇÃO QUE ELA EXERCE NA CONCREÇÃO DOS DIREITOS FUNDAMENTAIS}

O direito à propriedade é um direito natural do homem e essencial para sua sobrevivência, desenvolvimento e autonomia.

A propriedade em si não possui conceito e forma estáticos, sendo muito importante ter o conhecimento de que ela acompanha a dinâmica social da cidade e sofre influência dos sistemas jurídico-econômicos, políticos e inclusive religiosos.

O artigo 17 da Declaração dos Direitos dos Homens já dizia que a propriedade é um direito inviolável e sagrado. ${ }^{19}$

Inicialmente, a propriedade era um bem comum de todos, de cunho coletivo, que caminhou para um conceito majoritário de direito individual e absoluto, porém, hodiernamente, embora assegurada individualmente, deve atender a sua função social. ${ }^{20}$

As primeiras constituições a disporem sobre o princípio da função social da propriedade foram a Constituição do México de 1917 e a Constituição Alemã de Weimar, de 1919.

${ }^{19}$ ONU - ORGANIZAÇÃO DAS NACOES UNIDAS. Declaração de Direitos do Homem e do Cidadão. 1789. Disponível em <http://www.direitoshumanos.usp.br/index.php/Documentos-anteriores-\%C3\%A0cria\%C3\%A7\%C3\%A3o-da-Sociedade-das-Na\%C3\%A7\%C3\%B5es-at\%C3\%A9-1919/declaracao-de-direitosdo-homem-e-do-cidadao-1789.html>. Acesso em: 13 jul. 2019.

${ }^{20}$ TAVARES, André Ramos. Direito Constitucional Econômico. $2^{\text {a }}$. Ed. São Paulo: Editora Método, 2006. p. 150. 
Pelas lições de Vaz:

\begin{abstract}
Em princípio, a Constituição de 1919 garante a propriedade privada, cujos limites e conteúdo são atribuídos às leis ordinárias. [...] A estas limitações de natureza negativa, por assim dizer, segue-se uma disposição de cunho positivo, ao afirmar o texto que a propriedade deve, não apenas beneficiar seu titular, mas constituir, ao mesmo tempo, um serviço para o mais alto interesse comum. ${ }^{21}$
\end{abstract}

Outrossim, a inserção desta função passou por alguns percalços, em que o aspecto social tão almejado muitas vezes era confundido com os interesses do Estado.

Stolleis ${ }^{22}$ explica que "se uma sociedade busca funcionar harmoniosamente, uma autoridade se faz necessária", sendo neste ponto o grande percalço, devido a que esta autoridade sempre tendenciaria para o lado do "soberano".

No percurso da história, segundo o autor "o Estado abstrato tornou-se a materialização política entre a soberania do Monarca e a soberania do Povo", um fator importante para a garantia da liberdade, em que os juízes "estavam limitados a decidir apenas pelo Direito, mas eram independentes". 23

Ele ainda explica que mesmo com este aparato, "antes da metade do século, a Justiça ainda era encarada como uma ideia dissidente" e que "a Justiça cível providenciava a proteção contra intervenções arbitrárias na liberdade e na propriedade". ${ }^{24}$

Segundo Rolnik ${ }^{25}$ a igualdade para os liberais é "aquela que todos devem ter perante a lei de serem proprietários e de transferirem suas propriedades através do contrato" e, conclui, citando Bobbio "o direito privado ou dos privados é o direito do estado de natureza, cujos institutos fundamentais são a propriedade e o contrato".

Ainda, a Autora arremata que para o pensamento liberal, "a liberdade é função da propriedade, um governo responsável pela liberdade de seus cidadãos deve garantir a

\footnotetext{
${ }^{21}$ VAZ, Isabel. Direito Econômico das propriedades. $1^{a}$. Ed. Rio de Janeiro: Forense, 1992.p. 112- 113.

${ }^{22}$ STOLLEIS, Michael. Interpretação Judicial na Transição do ANCIEN RÉGIME para o Constitucionalismo. Trad. Rafael Tomaz de Oliveira. Ribeirão Preto: UNAERP, 2011.p. 01-02.

${ }^{23}$ STOLLEIS, Michael. Interpretação Judicial na Transição do ANCIEN RÉGIME para o Constitucionalismo. Trad. Rafael Tomaz de Oliveira. Ribeirão Preto: UNAERP, 2011.p. 15.

${ }^{24}$ STOLLEIS, Michael. Interpretação Judicial na Transição do ANCIEN RÉGIME para o Constitucionalismo. Trad. Rafael Tomaz de Oliveira. Ribeirão Preto: UNAERP, 2011.p. 15.

${ }^{25}$ ROLNIK, Raquel. Guerra dos Lugares: a colonização da terra e da moradia na era das finanças. $1^{a}$ Ed. São Paulo: Boitempo, 2015. p. 197.
} 
propriedade como uma de suas principais obrigações" e que "propriedade, direito e cidadania se entrelaçam". 26

A propriedade no Brasil, que, por seu valor e importância, está amparada e garantida pela Constituição Federal, em seu artigo $5^{\circ}$, inciso XXII, sendo um direito e uma garantia fundamental do cidadão, tendo seu exercício limitado pela função social da propriedade previsto no inciso XXIII.

Importante destacar que os incisos supra citados ainda orientam o Título VII, Capítulo II, Art. 170, da Ordem Econômica e Financeira do mesmo instituto, prescrevendo que a ordem econômica fundada na valorização do trabalho humano e na livre iniciativa, visa garantir a todos, condições de existência digna, atendendo princípios como o da propriedade privada e o da função social da propriedade.

O Direito à propriedade também está garantido pelo Código Civil no artigo 1.288:

\begin{abstract}
"Art. 1.228. O proprietário tem a faculdade de usar, gozar e dispor da coisa, e o direito de reavê-la do poder de quem quer que injustamente a possua ou detenha.

$\S 1^{\circ} \mathrm{O}$ direito de propriedade deve ser exercido em consonância com as suas finalidades econômicas e sociais e de modo que sejam preservados, de conformidade com o estabelecido em lei especial, a flora, a fauna, as belezas naturais, o equilíbrio ecológico e o patrimônio histórico e artístico, bem como evitada a poluição do ar e das águas."
\end{abstract}

Carlos Alberto Gonçalves citando Cunha Gonçalves definiu o direito de propriedade como "aquele que uma pessoa singular ou coletiva efetivamente exerce numa coisa determinada em regra perpetuamente, de modo normalmente absoluto, sempre exclusivo, e que todas as outras pessoas são obrigadas a respeitar". ${ }^{27}$

A função social da propriedade é princípio essencial do Direito Urbanístico, necessário para a concretização de um planejamento urbano ideal, que garanta o bem-estar comum, preocupado com todas as questões pertinentes ao uso correto do solo, garantindo a dignidade humana e a liberdade individual. Este princípio é o objetivo principal buscado pela política de desenvolvimento urbano, extraído do artigo 182 da CF:

\footnotetext{
${ }^{26}$ ROLNIK, Raquel. Guerra dos Lugares: a colonização da terra e da moradia na era das finanças. $1^{\text {a }}$ Ed. São Paulo: Boitempo, 2015. p. 197.

${ }^{27}$ GONÇALVES, Carlos Roberto. Direito Civil Brasileiro: Volume V - Direito das Coisas. $4^{a}$ Edição. São Paulo. Saraiva. 2009. p. 208.
} 
Art. 182, A política de desenvolvimento urbano, executada pelo Poder Público Municipal, conforme diretrizes gerais fixadas na lei, tem por objetivo ordenar o pleno desenvolvimento das funções sociais da cidade e garantir o bem-estar de seus habitantes.

A função social da propriedade também foi definida pela Política Nacional de Desenvolvimento Urbano, na $1^{\mathrm{a}}$ Conferência das Cidades expressando que:

\begin{abstract}
A propriedade urbana e a cidade devem cumprir sua função social, entendida como a prevalência do interesse comum sobre o direito individual de propriedade, contemplando aspectos sociais, ambientais, econômicos (de inclusão social) e a implantação combinada com os instrumentos do Estatuto da Cidade. ${ }^{28}$
\end{abstract}

Destaque-se a previsão do artigo 39 , caput e $\S 2^{\circ}$, da Lei $10.257 / 01$, que trata deste princípio no Estatuto da Cidade:

Art. 39. A propriedade urbana cumpre sua função social quando atende as exigências fundamentais de ordenação da cidade expressas no plano diretor, assegurando o atendimento das necessidades dos cidadãos quanto à qualidade de vida, à justiça social e ao desenvolvimento das atividades econômicas, respeitadas as diretrizes previstas no art. $2^{\circ}$ desta Lei.

(...)

$\S 2^{\circ}$, A política urbana tem por objetivo ordenar o pleno desenvolvimento das funções sociais da cidade e da propriedade urbana, mediante as seguintes diretrizes gerais: (...).

Deste modo, "a propriedade não é um direito subjetivo do proprietário, mas a função social do detentor da riqueza. Assim sendo, deve ele gerir a coisa, tendo em vista o seu melhor rendimento e no interesse de todos". ${ }^{29}$

Silva ${ }^{30}$ concluiu que "a função social da propriedade não se confunde com os sistemas de limitação da propriedade. Estes dizem respeito ao proprietário; aquela, à estrutura do direito mesmo, à propriedade".

Sob outro aspecto, Lehfeld e Oliveira ressaltam que a propriedade como direito fundamental tem como condição sine qua non para o seu exercício, não só o cumprimento de sua função social, mas também ambiental, citando, ainda, os ensinamentos de Diniz:

[...] a propriedade está impregnada de socialidade e limitada pelo interesse público. O atendimento ao princípio da função social da propriedade requer não só que seu uso seja efetivamente compatível com a destinação socioeconómica do bem, p. ex., se este for imóvel rural, nele dever-se-á exercer atividade agrícola, pecuária, agropecuária,

\footnotetext{
${ }^{28}$ MINISTÉRIO DAS CIDADES. Política Nacional de Desenvolvimento Urbano 1. Novembro, 2004. p. 77.

${ }^{29}$ HARADA, Kyoshi. Desapropriação - Doutrina e prática. 6. Ed. São Paulo: Atlas, 2006. p. 5.

${ }^{30}$ SILVA, José Afonso da. Curso de direito constitucional positivo. 25 ad. São Paulo: Malheiros, 2005. p. 281282.
} 
agroindustrial ou extrativa, mas também que sua utilização respeite o meio ambiente, as relações de trabalho, o bem-estar social e a utilidade de exploração. Deverá haver, portanto, uso efetivo e socialmente adequado da coisa. ${ }^{31}$

Na mesma medida, de acordo com o Direito de Propriedade, o proprietário, no uso de suas atribuições poderá usar, gozar, dispor e reaver da sua propriedade, desde que atenda a sua função social e ambiental. É um princípio que não dispõe de força coercitiva para ser atendido e, caso a Administração Pública detecte algum indício de violação, poderá tomar providências sobre o eventual infrator.

Sendo assim, o descumprimento da função socioambiental é uma violação da norma maior, ou seja, de um princípio constitucional.

Além da função socioambiental, outras limitações também estão expressas no ordenamento, como os institutos que regulam a utilização da propriedade e que possibilitam a intervenção do Estado no domínio privado.

A propriedade então, com a função socioambiental, teve seu contexto ampliado para as necessidades sociais e ambientais, comprometida com os direitos subjetivos de liberdade para a construção de uma sociedade justa e solidária. ${ }^{32}$

Ainda, para Lopes:

\begin{abstract}
A função social da propriedade e da empresa [...] não deixa de ser uma tentativa de inserir a solidariedade nas relações horizontais entre os indivíduos, transformando-os em responsáveis pela efetiva realização do projeto de uma sociedade de membros autônomos e iguais, inclusive no que diz respeito à redução das desigualdades sociais. $^{33}$
\end{abstract}

No entanto, para que o direito de propriedade seja exercido de forma adequada, o seu uso deverá ser efetivamente compatível com a destinação socioeconômica do bem e sua utilização deverá respeitar o meio ambiente, as relações de trabalho, o bem-estar social e a

\footnotetext{
${ }^{31}$ LEHFELD, Lucas de Souza; OLIVEIRA, Raul Miguel Freitas; ESTADO SOCIOAMBIENTAL DE DIREITO E O CONSTITUCIONALISMO GARANTISTA. o princípio in dubio pro natura como mecanismo de controle do ativismo judicial contrário à tutela dos direitos fundamentais ambientais. Maio. 2016. Disponível em: < https://www.conpedi.org.br/publicacoes/c50o2gn1/212559so/JUORPBaakN1ZQ94c.pdf >. Acesso em: 01 março 2019. p. 287.

${ }^{32}$ LOPES, Ana Frazão de Azevedo. Empresa e propriedade privada: função social e abuso de poder econômico. São Paulo: Quartier Latin, 2006. p. 122.

${ }^{33}$ LOPES, Ana Frazão de Azevedo. Empresa e propriedade privada: função social e abuso de poder econômico. São Paulo: Quartier Latin, 2006. p. 253.
} 
utilidade de exploração, a fim de se manter o ambiente equilibrado, garantindo-se a dignidade da pessoa humana e a liberdade individual.

Hodiernamente, diga-se que a propriedade, além de exercer o papel constituído pelos poderes do proprietário também deve funcionar no sentido de evitar uma subutilização da propriedade que possa gerar problemas como a exclusão social e perda da dignidade humana.

Concluindo, ao passo que a propriedade é um direito fundamental do proprietário sendo, por isso, um direito privado, a função socioambiental da propriedade implica um direito coletivo da sociedade de impor que a propriedade particular não viole os direitos da coletividade.

Portanto, unindo-se os pontos estudados até então, para que seja desenvolvida uma política urbana pautada na função socioambiental que deve exercer, que garanta melhores condições de vida para a população, uma cidade sustentável, é necessário que se desenvolva uma cultura de gestão participativa do cidadão, com o exercício pleno da democracia, o que fará garantir os direitos fundamentais da pessoa humana.

Neste passo, importante analisar a moradia como parte deste planejamento urbano ideal e as garantias que dela devem prevalecer como o direito à dignidade da pessoa humana.

\section{A MORADIA COMO ELEMENTO BÁSICO DA DIGNIDADE HUMANA}

O direito à moradia, a propriedade, a habitação são problemas e questões tratadas historicamente em diversos âmbitos, pela sua pluralidade de aspectos essenciais à vida humana.

Desde 1948, com a Declaração Universal dos Direitos Humanos, este direito é considerado fundamental, universal e que, além de figurar como condição capital para a vida digna, também atua em função de sua conexão direta com outros tantos direitos considerados essenciais para a dignidade da pessoa humana. 
Compreende-se o direito à moradia como um direito social de acesso, de igualdade, ligado incontestavelmente a dignidade humana, por ser uma condição mínima de efetividade deste fundamento constitucional.

Segundo o artigo 25 da Declaração dos Direitos Humanos: "Toda pessoa tem direito a um padrão de vida capaz de assegurar a si e a sua família saúde e bem-estar, inclusive alimentação, vestuário, habitação, cuidados médicos e os serviços sociais indispensáveis". ${ }^{34}$

Nesta esteira também se encontra o Pacto Internacional dos Direitos Econômicos, Sociais e Culturais, promulgado em 1996, dispondo em seu artigo 11 que os Estados que o assinaram "reconhecem o direito de toda pessoa a um nível de vida adequado para si próprio e sua família, inclusive à alimentação, vestimenta e moradia adequadas, assim como a uma melhoria contínua de suas condições de vida". 35

Além destes documentos, podemos destacar a Declaração de Vancouver sobre os assentamentos humanos - HABITAT I (1976), que estabeleceu o direito à moradia adequada como um direito básico da pessoa humana e, ainda, a Agenda HABITAT II (1996) que indicou diretrizes para elaboração de políticas relacionadas aos assentamentos humanos.

O direito à moradia foi consagrado no Texto Constitucional por força do disposto na Emenda Constitucional de $n^{\circ}$ 26, em 2000, assim dispondo em seu artigo 6 $6^{\circ}$ : "São direitos sociais a educação, a saúde, a alimentação, o trabalho, a moradia, o transporte, o lazer, a segurança, a previdência social, a proteção à maternidade e à infância, a assistência aos desamparados, na forma desta Constituição".

Sendo assim, pode-se concluir que a partir da entrada em vigor da emenda citada o Estado brasileiro está obrigado a traçar, conceber, implementar e executar políticas públicas que tornem a moradia um direito mínimo a cada cidadão. ${ }^{36}$

\footnotetext{
${ }^{34}$ ONU - ORGANIZAÇÃO DAS NACOES UNIDAS. Declaração Universal dos Direitos Humanos. 1948. Disponível em <http://www.direitoshumanos.usp.br/index.php/Declara\%C3\%A7\%C3\%A3o-Universal-dosDireitos-Humanos/declaracao-universal-dos-direitos-humanos.html>. Acesso em: 13 jul. 2019.

${ }^{35}$ ONU - ORGANIZAÇÃO DAS NACOES UNIDAS. Pacto Internacional sobre Direitos Econômicos, Sociais e $\begin{array}{llll}\text { Culturais. } & 1966 . & \text { Disponível } & \mathrm{em}\end{array}$ https://www.oas.org/dil/port/1966\%20Pacto\%20Internacional\%20sobre\%20os\%20Direitos\%20Econ\%C3\%B3m icos, \%20Sociais\%20e\%20Culturais.pdf >. Acesso em: 15 jul. 2019.

${ }^{36}$ INÁCIO, Gilson Luiz. Direito Social à Moradia \& a Efetividade do Processo: Contratos do Sistema Financeiro da Habitação. $1^{\text {a }}$ Edição. Curitiba. Juruá. 2002. p. 41.
} 
Segundo Seffrin e Cenci a moradia é:

um dos elementos essenciais da tríade alimentação/saúde/moradia que vai permitir que o ser humano tenha um padrão mínimo para viver com dignidade. É um direito que garante não só a proteção contra intempéries climáticas e contra perigos encontrados na natureza e nas ruas, mas, sobretudo, que garante abrigo ao pensamento, à privacidade, à expressão da individualidade, motivo pelo qual é reconhecido nacional e internacionalmente como um direito humano garantido a todos. ${ }^{37}$

Importante estabelecer a intenção do Estado Democrático de Direito como provedor destes direitos.

Em destaque às palavras de Bolsan de Morais citadas por Lênio Streck ao dizer que:

o Estado Democrático de Direito teria (tem?) a característica de ultrapassar não só a formulação do Estado Liberal de Direito, como também a do estado Social de Direito - vinculado ao Welfare State neocapitalista -, impondo à ordem jurídica e à atividade estatal um conteúdo utópico de transformação da realidade. ${ }^{38}$

Concomitantemente, o mesmo Autor define que o Estado Democrático de Direito:

emerge como um aprofundamento da fórmula, de um lado, do Estado de Direito, e, de outro, do Welfare State. Resumidamente, pode-se dizer que, ao mesmo tempo que se tem a permanência em voga da já tradicional questão social, há como que a sua qualificação pela questão da igualdade. Assim, o conteúdo deste se aprimora e se complexifica, posto que impõe à ordem jurídica e à atividade estatal um conteúdo utópico de transformação do status quo. Produz-se, aqui, um pressuposto teleológico cujo sentido deve ser incorporado aos mecanismos próprios ao Estado do bem-estar, construídos desde há muito. ${ }^{39}$

E ainda dispõe que “o Estado Democrático de Direito representa a vontade constitucional de realização do Estado Social. É um plus normativo em relação ao direito promovedor-intervencionista próprio do Estado Social de Direito". ${ }^{40}$

Com a leitura do artigo $3^{\circ}$ da Constituição Federal Tassinari e Oliveira dispõem sobre o fator social transformador advindo do novo Estado Democrático de Direito:

\footnotetext{
${ }^{37}$ SEFFRIN, Geciana; CENCI, Daniel Rubens. Dignidade da Pessoa Humana e Direito à Moradia Digna no Estado Democrático de Direito. Out. 2017. Disponível em: < file://C:/Users/Juliana/Downloads/8678-1-366821-10-20171227.pdf>. Acesso em: 13. jul 2019. p. 1-2.

${ }^{38}$ STRECK, Lênio Luiz. Jurisdição Constitucional e Decisão Jurídica. São Paulo: Editora Revista dos Tribunais, 2013. p. 100.

${ }^{39}$ STRECK, Lênio Luiz. Jurisdição Constitucional e Decisão Jurídica. São Paulo: Editora Revista dos Tribunais, 2013. p. 84-85.

${ }^{40}$ STRECK, Lênio Luiz. Jurisdição Constitucional e Decisão Jurídica. São Paulo: Editora Revista dos Tribunais, 2013. p. 101 .
} 
a Constituição brasileira de 1988 é tratada como uma constituição dirigente, porque traz consigo uma preocupação que vai muito além da manutenção do status quo ou da mera organização estatal. Muito acima disso, a nossa constituição vigente visa a ter, em si e por si mesma, uma capacidade de fomentar a transformação social, de modo que se propõe a estabelecer diretrizes, objetivos e fins a serem alcançados pelo Estado e pela sociedade, além de vincular o legislador ordinário à realização de políticas públicas que (não só, mas além de tudo) contribuam - direta ou indiretamente - para a redução gradativa das mazelas sociais presentes no Brasil contemporâneo. ${ }^{41}$

Por todo o exposto, é de se destacar que o direito à moradia tem associação direta com o princípio da dignidade da pessoa humana, fator que ensejou a sua inserção no rol dos direitos sociais da Constituição Federal.

Sendo assim, a dignidade humana é preceito fundamental e estrutural do Estado Democrático de Direito, ventilado pelo artigo $1^{\circ}$, inciso III da Carta Magna:

Art. $1^{\circ}$ A República Federativa do Brasil, formada pela união indissolúvel dos Estados e Municípios e do Distrito Federal, constitui-se em Estado Democrático de Direito e tem como fundamentos:

(...)

III - a dignidade da pessoa humana;

Este princípio também está reconhecido em outros dispositivos da Carta Magna, nos artigos 226, 227 e 230, relacionando a dignidade humana ao planejamento familiar.

Nesta ordem, constata-se que a dignidade humana é considerada essencial ao planejamento urbano para construção de moradias populares, saneamento básico e transporte público, pelo fato de que é a população mais carente quem sofre maiores prejuízos sociais.

Segundo Ingo Sarlet reconhecido o princípio da dignidade da pessoa humana como um dos fundamentos do Estado Democrático de Direito "reconheceu-se categoricamente que é o Estado que existe em função da pessoa humana, e não o contrário, já que o ser humano constitui finalidade precípua, e não meio da atividade estatal". ${ }^{4}$

\footnotetext{
${ }^{41}$ TASSINARI, Clarissa; OLIVEIRA, Rafael Tomaz de. Judicialização da Política e Ativismo Judicial. Notas para uma necessária diferenciação. 2013.2 Disponível <file:///C:/Users/Juliana/Downloads/2013_Livro\%20Canotilho_Tassinari\%20e\%20Tomaz\%20de\%20Oliveira.p df> Acesso em: 08 jun 2019. p. 11.

${ }^{42}$ SARLET, Ingo Wolfgang. Dignidade da pessoa humana e direitos fundamentais. 9. ed. Porto Alegre: Livraria do Advogado, 2011. p.80.
} 
Contudo, é dever do Estado garantir o mínimo existencial aos cidadãos. Porém, mesmo com a existência de legislação garantindo o direito à moradia digna, esta ainda encontra muitas barreiras sociais.

Conforme Rolnik os desafios urbanísticos não são poucos, por não se tratar apenas de expansão da infra-estrutura nas cidades como forma de absorção de um crescimento futuro, eis que a base do processo de urbanização consolidou um modelo marcado por imensas disparidades socioespaciais e grande degradação ambiental, "periferia" e "favela" ainda são categorias urbanísticas e culturais fortes. ${ }^{43}$

Para a urbanista "as dinâmicas recentes têm desafiado as cidades a absorver o crescimento, melhorando suas condições de urbanização de modo a sustenta-lo do ponto de vista territorial”. E ainda retrata que "o Brasil não teve nada parecido com um sistema de bemestar ao longo de sua história" [...] “o Estado desenvolvimentista do período do pós-guerra não teve um arranjo comparável no Brasil". ${ }^{4}$

Ela ainda aduz que "esse modelo desenvolvimentista e socialmente perverso resultou na consolidação de uma das sociedades mais desiguais do mundo, em que a maioria da população não tem atendidas necessidades básicas, tal como a habitação". 45

Para Ingo Sarlet a falta de uma moradia decente pode acabar comprometendo gravemente ou definitivamente os pressupostos básicos para uma vida com dignidade. ${ }^{46}$

Complementando a legislação com as garantias ao direito à moradia digna está o Comentário Geral número 4 emitido pelo Comitê dos Direitos Econômicos, Sociais e Culturais da ONU, que enumerou fatores sobre o que seria uma moradia adequada enquanto elemento da dignidade da pessoa humana, quais sejam: segurança jurídica da posse, disponibilidade de

\footnotetext{
${ }^{43}$ ROLNIK, Raquel. Guerra dos Lugares: a colonização da terra e da moradia na era das finanças. $1^{\text {a }}$ Ed. São Paulo: Boitempo, 2015. p. 266.

${ }^{44}$ ROLNIK, Raquel. Guerra dos Lugares: a colonização da terra e da moradia na era das finanças. $1^{\text {a }}$ Ed. São Paulo: Boitempo, 2015. p. 266.

${ }^{45}$ ROLNIK, Raquel. Guerra dos Lugares: a colonização da terra e da moradia na era das finanças. $1^{\mathrm{a}}$ Ed. São Paulo: Boitempo, 2015. p. 267.

${ }^{46}$ SARLET, Ingo Wolfgang. Dignidade da pessoa humana e direitos fundamentais. 9. ed. Porto Alegre: Livraria do Advogado, 2011. p. 133.
} 
serviços, materiais, instalações e infraestrutura, economicidade, habitabilidade, acessibilidade, localização e adequação cultural.

Assim, considera-se moradia adequada àquela que preencher os requisitos enumerados neste documento, rechaçando-se qualquer forma de interpretação restritiva a este direito.

Como se pode notar são muitos os requisitos necessários para que se alcance a moradia digna, lembrando que ela não se atém apenas à ideia de habitação, devido à sua relação com a qualidade de vida das pessoas, passando para um patamar muito maior e mais complexo que este.

Porém, estas garantias estão muito longe de serem alcançadas como bem coloca Lênio Streck "estamos em face de um sério problema: de um lado, temos uma sociedade carente de realização de direitos e, de outro, uma Constituição que garante estes direitos da forma mais ampla possível". ${ }^{47}$

Neste diapasão, Raquel Rolnik, ao atuar como relatora especial para o direito à moradia adequada da Organização das Nações Unidas (ONU), conta que durante sua experiência:

\begin{abstract}
a propriedade imobiliária em geral e a habitação em particular configuram uma das mais novas e poderosas fronteiras da expansão do capital financeiro. A crença de que os mercados podem regular a alocação da terra urbana e da moradia como forma mais racional de distribuição de recursos, combinada com produtos financeiros experimentais e "criativos" vinculados ao financiamento do espaço construído, levou às políticas públicas a abandonar os conceitos de moradia como um bem social e de cidade como um artefato público. As políticas habitacionais e urbanas renunciaram ao papel de distribuição de riqueza [...] para se transformarem em mecanismo de extração de renda, ganho financeiro e acumulação de riqueza. Esse processo resultou na despossessão massiva de territórios, na criação de pobres urbanos "sem lugar", em novos processoS de subjetivação estruturados pela lógica do endividamento, além de ter ampliado significativamente a segregação nas cidades. ${ }^{48}$
\end{abstract}

Desta forma, podemos concluir que mesmo com todo aparato legislativo nacional e internacional de garantia ao direito à moradia digna, com conceito ampliado, não englobando somente a habitação, o Poder Público ainda é omisso na sua aplicação. E isto se dá devido ao interesse mercadológico e à exclusão urbanística cultural, o que deve ser amplamente

\footnotetext{
${ }^{47}$ STRECK, Lênio Luiz. Jurisdição Constitucional e Decisão Jurídica. São Paulo : Editora Revista dos Tribunais, 2013. p. 100.

${ }^{48}$ ROLNIK, Raquel. Guerra dos Lugares: a colonização da terra e da moradia na era das finanças. $1^{a}$ Ed. São Paulo: Boitempo, 2015. p. 14-15.
} 
combatido a fim de se proporcionar a inclusão dos direitos fundamentais, sociais e ambientais, que por suas razões também há de se destacar.

\section{CONCLUSÃO}

A cidade vem sendo cada vez mais uma preocupação no que tange aos problemas urbanos, causados em grande parte pela rápida ocupação e falta de planejamento.

O crescimento acelerado sem padrões de construção e obediência aos direitos fundamentais vem gerando muitos problemas de cunho social, transformando o ambiente urbanístico em um verdadeiro caos, chamado pelos estudiosos de "Crise Urbana".

Apresentou-se o planejamento urbano como um elemento importante capaz de organizar a cidade na tentativa de proporcionar melhores condições de vida à população e consequentemente reduzir a discriminação e as desigualdades sociais.

Saliente-se que no processo de desenvolvimento da cidade, é necessário que ela atenda à sua função social, que o solo seja parcelado de acordo com as diretrizes urbanísticas e princípios fundamentais, fazendo com que a propriedade respeite sua função socioambiental a fim de prevalecer o interesse comum e não o particular.

O ordenamento jurídico brasileiro institui instrumentos e diretrizes capazes de assegurar à população o mínimo existencial, uma maior qualidade de vida, um ambiente ecologicamente equilibrado, uma cidade sustentável, além de que todas as disposições normativas referentes ao planejamento, ordenamento e gestão dos espaços urbanos tem o escopo de concretizar o valor da dignidade da pessoa humana.

Destacou-se o direito à moradia como fator essencial de concreção da dignidade humana, que abrange não só a habitação, mas todo o aparato para alcançar o mínimo existencial.

Contudo, demonstrou que embora o direito a moradia com dignidade possua vasto aparato legislativo nacional e internacional, fatores como a omissão do poder público e a falta 
de interesse da população na elaboração, implementação e fiscalização das decisões, tornam-se precursores para a sua inefetividade e ocasionam inúmeras consequências que geralmente atingem a população de baixa renda, que normalmente é alocada nas periferias e favelas, como desigualdades sociais, inundações, desmoronamentos e criminalidade.

Como solução a este problema entendeu-se que é necessário a atuação da população junto à Administração Pública, a fim de garantir que os interesses da população sejam atendidos e implementados, resgatando a cultura participativa, eis que os planos e interesses da população precisam sair do papel.

Assim, concluiu-se que a melhor forma de promover o direito à moradia digna é por meio do planejamento urbano, que deve ser elaborado com vistas à melhor qualidade de vida da população e com a participação da sociedade que indicará os seus anseios e necessidades ao Poder Público, mas, para tanto, a sociedade precisa resgatar a cultura participativa na gestão dos atos do Poder Público.

\section{REFERÊNCIAS BIBLIOGRÁFICAS}

BOBBIO, Norberto. A era dos direitos. Trad. Carlos Nelson Coutinho. Rio de Janeiro: Campus, 1992.

BRASIL. Constituição da República Federativa do Brasil de 1988. Disponível em < http://www.trtsp.jus.br/legislacao/constituicao-federal-emendas>. Acesso em 05 jul. 2019.

BRASIL. Lei 10.257, DE jul. 2001. Estatuto da Cidade. Brasília-DF, jul. 2001. Disponível em < http://www.planalto.gov.br/ccivil_03/leis/LEIS_2001/L10257.htm> Acesso em: 10 jul 2019.

BRASIL. Lei 10.406, de jan. 2002. Código Civil. Brasília - DF, jan. 2002. Disponível em < http://www.planalto.gov.br/ccivil_03/LEIS/2002/L10406.htm>. Acesso em 13 jul 2019.

CASTELLS, Manuel. A Questão urbana. 3. ed. Rio de Janeiro: Paz e Terra, 1983.

GONÇALVES, Carlos Roberto. Direito Civil Brasileiro: Volume V - Direito das Coisas. $4^{\mathrm{a}}$ Edição. São Paulo. Saraiva. 2009

HARADA, Kyoshi. Desapropriação - Doutrina e prática. 6. Ed. São Paulo: Atlas, 2006. 
INÁCIO, Gilson Luiz. Direito Social à Moradia \& a Efetividade do Processo: Contratos do Sistema Financeiro da Habitação. 1ª Edição. Curitiba. Juruá. 2002.

LEHFELD, Lucas de Souza; OLIVEIRA, Raul Miguel Freitas; ESTADO SOCIOAMBIENTAL DE DIREITO E O CONSTITUCIONALISMO GARANTISTA. 0 princípio in dubio pro natura como mecanismo de controle do ativismo judicial contrário à tutela dos direitos fundamentais ambientais. Maio. 2016. Disponível em: < https://www.conpedi.org.br/publicacoes/c50o2gn1/212559so/JUORPBaakN1ZQ94c.pdf>. Acesso em: 01 março 2019.

LOPES, Ana Frazão de Azevedo. Empresa e propriedade privada: função social e abuso de poder econômico. São Paulo: Quartier Latin, 2006.

MARICATO, Ermínia. Brasil 2000: qual planejamento urbano?. Cadernos IPP UR, Rio de Janeiro, Ano XI, Nos 1 e 2, 1997. Disponível em: < https://erminiamaricato.files.wordpress.com/2016/12/cadernos-ippur.pdf $>$. Acesso em: 10 jul 2019.

MARICATO, Ermínia. As ideias fora do lugar e o lugar fora das ideias. Planejamento urbano no Brasil. In: ARANTES, Otília; VAINER, Carlos; MARICATO, Ermínia. A cidade do pensamento único. $8^{\mathrm{a}}$. ed. Petrópolis: Vozes, 2013.

MARICATO, Ermínia. O impasse da política urbana no Brasil. $3^{\text {a }}$. ed. Petrópolis: Vozes, 2014.

MEIRELLES, Hely Lopes. Direito Municipal Brasileiro. Malheiros. 16. ed. São Paulo: 2008.

MINISTÉRIO DAS CIDADES. Política Nacional de Desenvolvimento Urbano 1. Novembro, 2004.

MUKAI, Toshio. Direito urbano-ambiental brasileiro. 2. ed. Rev. e ampl. São Paulo: Ed. Dialética, 2002.

ONU - ORGANIZAÇÃO DAS NACOES UNIDAS. Declaração de Direitos do Homem e do Cidadão. 1789. Disponível em <http://www.direitoshumanos.usp.br/index.php/Documentosanteriores-\%C3\%A0-cria\%C3\%A7\%C3\%A3o-da-Sociedade-das-Na\%C3\%A7\%C3\%B5esat\%C3\% A9-1919/declaracao-de-direitos-do-homem-e-do-cidadao-1789.html>. Acesso em: 13 jul. 2019.

ONU - ORGANIZAÇÃO DAS NACOES UNIDAS. Declaração Universal dos Direitos Humanos. $1948 . \quad$ Disponível em <http://www.direitoshumanos.usp.br/index.php/Declara\%C3\%A7\%C3\%A3o-Universal-dosDireitos-Humanos/declaracao-universal-dos-direitos-humanos.html>. Acesso em: 13 jul. 2019.

ONU - ORGANIZAÇÃO DAS NACOES UNIDAS. Pacto Internacional sobre Direitos Econômicos, Sociais $\quad \boldsymbol{e} \quad$ Culturais. $1966 . \quad$ Disponível em < https://www.oas.org/dil/port/1966\%20Pacto\%20Internacional\%20sobre\%20os\%20Direitos\% 20Econ\%C3\%B3micos,\%20Sociais\%20e\%20Culturais.pdf >. Acesso em: 15 jul. 2019. 
ONU - ORGANIZAÇÃO DAS NACOES UNIDAS. Comentário Geral no 4 do Comitê de Direitos Econômicos, Sociais e Culturais. 1991. Disponível em < http://acnudh.org/wpcontent/uploads/2011/06/Compilation-of-HR-instruments-and-general-comments-2009PDHJTimor-Leste-portugues.pdf >. Acesso em: 13 jul. 2019.

ROLNIK, Raquel. O que é cidade. $4^{\text {a }}$ Ed. São Paulo: Brasiliense, 2012.

ROLNIK, Raquel. Guerra dos Lugares: a colonização da terra e da moradia na era das finanças. $1^{\text {a }}$ Ed. São Paulo: Boitempo, 2015.

SARLET, Ingo Wolfgang. Dignidade da pessoa humana e direitos fundamentais. 9. ed. Porto Alegre: Livraria do Advogado, 2011.

SEFFRIN, Geciana; CENCI, Daniel Rubens. Dignidade da Pessoa Humana e Direito à Moradia Digna no Estado Democrático de Direito. Out. 2017. Disponível em: < file:///C:/Users/Juliana/Downloads/8678-1-36682-1-10-20171227.pdf>. Acesso em: 13. jul 2019.

SILVA, José Afonso da. Curso de direito constitucional positivo. 25 $5^{\text {a }}$ Ed. São Paulo: Malheiros, 2005.

STOLLEIS, Michael. Interpretação Judicial na Transição do ANCIEN RÉGIME para o Constitucionalismo. Trad. Rafael Tomaz de Oliveira. Ribeirão Preto: UNAERP, 2011.

STRECK, Lênio Luiz. Jurisdição Constitucional e Decisão Jurídica. São Paulo: Editora Revista dos Tribunais, 2013.

TASSINARI, Clarissa; OLIVEIRA, Rafael Tomaz de. Judicialização da Política e Ativismo Judicial. Notas para uma necessária diferenciação. 2013. Disponível em: <file:///C:/Users/Juliana/Downloads/2013_Livro\%20Canotilho_Tassinari\%20e\%20Tomaz\%2 0de\%20Oliveira.pdf $>$ Acesso em: 08 jun 2019.

TAVARES, André Ramos. Direito Constitucional Econômico. 2a. Ed. São Paulo: Editora Método, 2006.

VAZ, Isabel. Direito Econômico das propriedades. 1ª Ed. Rio de Janeiro: Forense, 1992.

WOLFF, Simone. Estatuto da Cidade: A Construção da Sustentabilidade..., Revista Jurídica Virtual - Brasília, vol. 4, n. 45, fev. 2003. Disponível em https://revistajuridica.presidencia.gov.br/index.php/saj/article/view/754/745. Acesso em 13 jul 2019.

Data de Submissão: 20/07/2020

Data de Aceite: $22 / 10 / 2020$ 